\title{
STRATEGIC ASPECTS OF QUALITY: A THEORETICAL ANALYSIS*
}

\author{
RAM NARASIMHAN AND DAVID MÉNDEZ \\ Department of Management, The Eli Broad Graduate School of Business, \\ Michigan State University, East Lansing, Michigan 48824-1122, USA \\ Department of Health Management and Policy, School of Public Health, \\ The University of Michigan, Ann Arbor, Michigan, 48109-2029, USA
}

\begin{abstract}
This paper investigates the relationship between aspects of quality and long run profitability and growth of a firm. The paper first determines whether a stable relationship among price, aspects of quality, and the sales rate exists, by examining the equilibrium properties of a dynamic model. Then, we use the derived equilibrium expressions to develop insights into the strategic nature of "quality reputation" and, how to integrate marketing (i.e., pricing) and quality related decisions. The paper shows under certain conditions it might be more advantageous to manipulate "quality reputation" through advertising and product innovations than to increase product quality. We comment on quality based strategic options a firm must consider to ensure long run growth and profitability.

(QUALITY; QUALITY REPUTATION; SALES RATE; EQUILIBRIUM ANALYSIS; DYNAMIC MODELS)
\end{abstract}

\section{Introduction}

There is little dispute as to the importance of quality for gaining competitive advantage. Surveys indicate that both American and European managers rank improving product and process quality among their top priorities (Fortuna 1990; Kim 1994). While research addressing the effect of quality on sales performance has been examined recently in the literature (Flynn, Schroeder, and Sakakibara 1995), this research does not consider the strategic effect of quality on long run sales growth and profitability of a firm. Most of the research in this area uses cross-sectional data analysis to identify correlation between quality and market performance, ignoring the feedback between quality improvements and the market response to such improvements. The relationship between quality and market performance is essentially dynamic. The market reacts not only to the tangible aspects of a product's quality, but also to the "quality reputation" that is perceptual and based on the tangible aspects of quality. This contention accords well with the integrative theory of strategic quality management and the model of "evaluative judgment," discussed by Wacker (1989). Wacker's conceptualization, utilizing an integrative model of evaluative judgment, proposes that specific features of the product (the objective aspects of quality) are perceived over time by consumers leading to an overall perception of product quality. Wacker states that "The hypothesis suggested here is that quality of a product is related not only to the

* Received February 2000; revision received September 2000; accepted September 2000. 
current features but also to past features. In simple terms, this hypothesis suggests that customers' previous product experience affects their perception of current overall quality. Consequently, it is important to include past features to estimate the overall quality of a product." Wacker goes on to observe that ". . . more likely, a product's improved quality will take several periods of good performance before customers will recognize its performance as being related to quality." He operationalizes this conceptualization utilizing a distributive lag function to define perceived quality as a composite index as follows:

$$
I N D E X_{t}=\sum_{i=1}^{n} \sum_{s=0}^{t} \alpha_{i, t-s} F E A T_{i, t-s}+e_{t}
$$

where $\left(I N D E X_{t}\right)$ represents customers' overall perception of quality, $\left(\alpha_{i, t-s}\right)$ is the effect of the $i$ th feature from the $(t-s)$ period in time on time period $(t),(s)$ represents the lag away form the current time period, and $\left(F E A T_{i, t-s}\right)$ represents feature $(i)$ at time period $(t-s)$ and $\left(e_{t}\right)$ is error term (Wacker 1989).

The model analyzed in this paper is akin to the model proposed by Wacker with some notable exceptions. Wacker's model development leads to statistical estimation of the weights associated with the "features" in a distributive lag model. The model analyzed in this paper, in contrast, captures similar ideas utilizing nonlinear, dynamical systems approach. For example, the notion of perceived quality as an accumulation of quality perceptions over a period of time is captured by a first-order exponential delay in the dynamic version of the model. The differential weights associated with past features in a distributive lag model discussed by Wacker, are analogously captured in the first-order delay (this is fully discussed in Mendez and Narasimhan 2000). The dynamic model analyzed in this paper utilizes the concept of "quality durability" in modeling perceived quality. Perceived quality is determined over time by actual quality, but other factors, such as advertisement, promotion and price as a signal of quality can also influence this relationship. This dynamic aspect of the quality-perceived quality relationship is not captured in Wacker's evaluative judgment model.

To elaborate, conceptually, each unit of a product that is sold can be thought of as carrying with it a "quantum" of quality message depending on the level of quality; the higher the quality level of each unit in the market, the higher the contribution to the quality reputation or perceived quality of the product. Intensely promoting enhancements in the quality of a product can be expected to increase the speed at which customers become aware of the improved quality, affecting perceived quality or quality reputation of the product. An important factor in the relationship between actual and perceived quality is product durability. The durability of products affects market saturation and influences the rate at which new units of the product enter the market. Other things being equal, the shorter the life of a product, the larger the number of potential customers who at a given time will not own it and, therefore, be willing to buy it. It can be argued that this effect of durability on new sales influences the speed at which customers become aware of changes in the product's quality. In addition, the longer each unit of the product stays in the market, the longer it continues to influence the (perceived quality) quality reputation of the product. In the remainder of the paper, we use the term quality reputation in preference to perceived quality. Although product durability can be subsumed under Wacker's model as one of the design features incorporated into the product, the model proposed by him does not explicitly focus on the important dynamics stemming from the interaction of product durability, saturation effect on demand, and its influence on the speed of diffusion of quality improvements. The impact of product durability on the relationship between quality and sales performance was recognized by Narasimhan, Ghosh, and Mendez (1993) in a model of the dynamic relationship among price, quality, and the sales rate. Besides recognizing the effect of product durability on sales, their research introduced the concept of "quality durability," or "quality life," as a factor that 
regulates the relationship between quality and sales performance. The authors conjectured that each of unit of a product in the market does not have the same capability to influence potential customers at all times during its useful life. In some cases, old units of a product regardless of their quality will not be representative of new units of the product with different quality attributes and therefore cannot influence the buying decisions of potential customers. In other cases where the quality level of products is sufficiently high, it can be asserted that the quality life of a unit can exceed its physical life, and that it can continue to influence the buying decisions of potential customers. Narasimhan modeled quality durability as a concept distinct and different from the "physical" durability of the product. The subsequent analysis shows that this distinction has important implications for quality based growth strategies.

This model was used in a subsequent work by Narasimhan, Mendez, and Ghosh (1996) to study the nature of optimal price trajectories under continuous quality improvement. The results of the study suggested that product durability and quality durability exert a significant influence on optimal pricing and sales performance. However, since the focus of their study was optimal pricing, the authors analyzed only the transient responses from their model in the paper. However, the relationship among product durability, quality durability (as it relates to quality reputation), long run profitability, and sales response (as it relates to business growth) cannot be clearly discerned from the optimal price trajectories.

This paper investigates the relationship between quality and, long run profitability and sales growth of a firm. The research builds on Narasimhan et al.'s prior work in the literature examining dynamic relationships among quality, and the market-related measures-sales response and profitability. The paper first determines whether a stable relationship among price, aspects of quality, and the sales rate exists, by examining the equilibrium properties of the dynamic model. Then, we use the derived equilibrium expressions to develop insights into the strategic nature of product durability and quality durability and how to and why integrate marketing and quality related decisions. The results show the strategic importance of "quality reputation," and that strategically, under some conditions, it might be more important to increase the content of the quality message that units carry into the market than to adopt promotional strategies. This notion also suggests that under some conditions it might be better to switch to strategies that are not quality based. We also examine what qualitybased strategic options a firm must consider to ensure long run growth and profitability. The practical relevance of the findings is discussed. It is important to note that even though this paper concentrates on stable, steady-state conditions, it recognizes the dynamic relationships under investigation. The effects of these dynamic relationships are still present in the steady-state conditions. From a theoretical point of view, this study postulates new relationships, that link concepts from economics (price, elasticity), marketing (sales rate, market potential), and manufacturing (quality, durability) and thus contributes to the understanding of the subject and opens potential areas for research. From a practical perspective, steady-state conditions apply to a great number of established products (e.g., home appliances and automobiles), and therefore the insights based on the results would be of potential interest to practitioners.

The remainder of the paper is organized as follows. The next section contains a brief review of relevant literature. The steady-state analysis of the dynamic model and the ensuing results are presented next. The main results of the theoretical analysis and their implications for understanding the strategic nature of quality are then presented. In the concluding section we discuss possible extensions of this work.

\section{Related Literature}

The strategic relationship between product quality and business growth and long run profitability remains essentially unresearched in the operations management literature. However, the dynamic relationship between quality and price as a determinant of sales has been receiving some attention in the literature. Tapiero, Ritchken, and Reisman (1987) proposed a 
framework for examining the tradeoffs among product pricing, reliability, design, and quality control issues. The authors used a "risk management" approach to compare alternative quality control schemes and pricing under stochastic demand. The authors address quality from an operational perspective. Banker and Khosla (1992) consider oligopolistic competition in a model that investigates whether equilibrium levels of quality increase as competition intensifies. The authors do not explicitly consider the dynamic interaction between quality and sales response. Lee and Tapiero (1986) assess the effects of quality control on sales. Given a set of "sales parameters" the authors show what the effects will be on quality control.

Another stream of research in the literature investigates price-quality relationship. The main focus of these papers is the investigation of the presumed positive relationship between price and quality, and higher price as a signal of higher quality. Monroe and Dodds (1988) provide an excellent review and assessment of marketing literature dealing with this topic. The authors conclude that investigation of price-quality relationship is incomplete and suggest that the dynamic relationship between price and quality merits a richer conceptualization. Rao and Monroe (1989) have conducted a meta-analysis of experimental studies in marketing to examine the relationship between price and perceptions of product quality. Their study concluded that there is a positive, statistically significant relationship between price and perceived quality. It is useful to note that our conceptualization of quality reputation and perceived quality is derived from entirely different and fundamental arguments concerning the sales process. Dodds, Monroe, and Grewal (1991) have studied the effect of price on product evaluations by customers including perceived quality. The authors used a designed experiment to pursue their investigation. Gerstner (1985) empirically investigated the relationship between price and quality and concluded that the relationship was weak. Narasimhan and Ghosh (1994) develop an optimal control model to study the effect of quality on optimal pricing and advertising decisions. The authors present qualitative characterizations of the nature of optimal price and advertising policies. Narasimhan, Mendez, and Ghosh (1996) used a dynamic model to investigate optimal price trajectories under continuous quality improvements.

Diffusion models that incorporate pricing stem from Bass (1969) model of new product diffusion. Mahajan, Muller, and Bass (1990) present an excellent review of diffusion models and suggest new directions for research. More recently, extensions of Bass diffusion models have been discussed by Bas, Krishnan, and Jain (1994) and Krishnan, Bass, and Jain (1999). Narasimhan, Ghosh, and Mendez (1993) presented a dynamic model (hereafter referred to as the NGM model) that included quality considerations in modeling the sales response for a product. The NGM model was shown to have conceptual validity in that the estimated parameter values accorded well with observed values and explained approximately 74 percent of the variation in actual sales data for a durable good. However, the authors did not present any theoretical analysis of their model or focus on the strategic insights that are embedded in such an analysis. The objective of this paper is not development of hypotheses or to propose an integrative theory but to develop theoretical insights into the strategic aspects of quality embedded in the NGM model.

\section{The NGM Model}

The NGM model is a modification and extension of the Bass (1969) diffusion model for new products. Bass diffusion model states that the sales rate of a product is proportional to both the number of units in the market and the difference between the number of units in the market and the market potential for the product. Market potential is defined as the maximum number of units of the product that can be sold. The model considered here extends Bass' equation by:

- modeling the market potential as a function of price;

- recognizing the limited life-span of products (which after some time free up potential buyers) and; 
- recognizing the feedback relationship between the market's perception of product quality and sales rate.

The mathematical formulation of the NGM model is as follows:

$$
\begin{gathered}
M\left(P_{t}\right)=\left(\frac{P_{0}}{P_{t}}\right)^{e} M_{0} \\
Q_{t}=D 1 \times Y_{t} \\
\frac{\mathrm{d}}{\mathrm{d} t} X_{t}=\frac{1}{D 2}\left(q_{t} \times S_{t}-X_{t}\right) \\
\frac{\mathrm{d}}{\mathrm{d} t} Y_{t}=\frac{1}{D 1}\left(S_{t}-Y_{t}\right) \\
E Q_{t}=D 2 \times X_{t} \\
S_{t}=\alpha \times E Q_{t} \times\left(M_{P}-Q_{t}\right)
\end{gathered}
$$

The following notations are used in the ensuing discussion.

$P_{t}=$ Price [\$]

$P_{0}=$ Base Price $[\$]$

$q_{t}=$ Quality index [0 to 1]

$M_{t}=$ Market Potential [units]

$M_{0}=$ Market Potential at Base Price [units]

$Q_{t}=$ Quantity of units in the market [units]

$S_{t}=$ Sales Rate [units/time]

$Y_{t}=$ Rate at which units leave the market [units/time]

$X_{t}=$ Rate at which the quality weighted quantity of goods in the market ceases to influence consumers' behavior [units/time]

$E Q_{t}=$ Quality weighted quantity of goods in the market [units]

$D 1=$ Average life of the units [time]

$D 2$ = Average time of the effect of quality of goods on consumer's buying behavior (quality durability).

$e=$ Price elasticity of demand.

$\alpha=$ Proportionality constant used to calculate sales rate [time-units] ${ }^{-1}$

$\beta=P_{0}^{e} \times M_{0}$

For a fuller discussion of the mathematical development of the model the reader is referred to Mendez and Narasimhan (2000). Succinctly, the quality-weighted units in the market $(E Q)$, which relates to quality reputation of the product, are assumed to generate the sales rate $(S)$ according to a "diffusion process." The computation of $E Q$ is accomplished by multiplying the sales rate $(S)$ by the quality level $(q)$, of the units entering the market and integrating the product $q * S$ along a distributed delay (Forrester 1968; Manetsch and Park 1982) that represents the length of time that the quality of a unit continues to affect sales by influencing customer perceptions of quality; the distributed delay is parameterized by the value $D 2$, which represents the average length of time during which the quality of a product influences new sales. Also, the sales rate is integrated within another delay that represents the lifespan of the product, to compute the number of units currently in the market $(Q)$. This delay is parameterized by the value $D 1$, which represents the average lifespan of the product. $Q$ and $E Q$ feed back into the diffusion equation to generate the sales rate for the product.

Taking $Q$ and $E Q$ as state variables, the state space representation of the model is:

$$
\frac{\mathrm{d} Q}{\mathrm{~d} t}=\alpha \beta\left(E Q_{t}\right) P_{t}^{-e}-\alpha\left(E Q_{t}\right) Q_{t}-\frac{Q_{t}}{D 1} \quad Q(0)=Q_{0}
$$




$$
\frac{\mathrm{d} E Q}{\mathrm{~d} t}=\alpha \beta q_{t}\left(E Q_{t}\right) P_{t}^{-e}-\alpha q_{t}\left(E Q_{t}\right) Q_{t}-\frac{\left(E Q_{t}\right)}{D 2} \quad E Q(0)=E Q_{0}
$$

\section{Steady-State Analysis}

In this section the long run behavior of the model is studied under conditions of constant price and constant quality. In particular, we assess:

- whether the model approaches an equilibrium point(s) asymptotically and;

- the dependence of the model's long run behavior on the specific values of the parameters of the model.

In order to investigate the equilibrium points of the system under conditions of constant price and quality, we set to zero the time derivatives of the state variables. Given that market potential (a function of price) and quality are both constant, we have omitted the subscript $t$ in the representation of these variables.

$$
\begin{gathered}
\frac{\mathrm{d} Q}{\mathrm{~d} t}=\alpha\left(E Q_{t}\right) M-\alpha\left(E Q_{t}\right) Q_{t}-\frac{Q_{t}}{D 1}=0 \\
\frac{\mathrm{d} E Q}{\mathrm{~d} t}=\alpha q\left(E Q_{t}\right) M-\alpha q\left(E Q_{t}\right) Q_{t}-\frac{\left(E Q_{t}\right)}{D 2}=0
\end{gathered}
$$

where $M$ is the constant market potential.

Let $\vec{\omega}=\left[\begin{array}{ll}Q & E Q\end{array}\right]^{\prime}$. Then the above system of equations can be expressed as $\dot{\vec{\omega}}=f(\vec{\omega})$ $=0$, with solutions:

$$
\begin{gathered}
\text { a) } \begin{array}{l}
Q^{a}=0 \\
E Q^{a}=0
\end{array} \\
\text { b) } \begin{array}{l}
Q^{b}=M-\frac{1}{\alpha D 2} \\
E Q^{b}=M q \frac{D 2}{D 1}-\frac{1}{\alpha D 1}=q \frac{D 2}{D 1}\left(M-\frac{1}{\alpha q D 2}\right)
\end{array}
\end{gathered}
$$

It can be noticed that $Q^{b}, E Q^{b}$ and $[M-(1 / \alpha q D 2)]$ are of the same sign. From the last expression, we can derive the following relationship between the sign of $Q^{b}$ and $E Q^{b}$, and the quality level $q$ :

$$
\begin{array}{ll}
q>\frac{1}{\alpha M D 2} \Rightarrow Q^{b} & E Q^{b}>0 \\
q<\frac{1}{\alpha M D 2} \Rightarrow Q^{b} & E Q^{b}<0 \\
q=\frac{1}{\alpha M D 2} \Rightarrow Q^{b} & E Q^{b}=0
\end{array}
$$

These results are stated without proof since our emphasis in this paper is to develop an understanding of the strategic implications of these results. Interested readers can contact the authors for proofs of these theoretical results.

The stability analysis shows the existence of an asymptotic, globally stable equilibrium point in the system. To illustrate the stability properties of the equilibrium point, the model is parameterized with the following values:

$$
D 1=7 \text { years, } D 2=2 \text { years, } M=2,000,000 \text { units, and } \alpha=0.001424 \text { [units-years] }^{-1}
$$


and a phase portrait diagram showing the trajectories followed by the state of the system for various initial conditions is constructed. This visual analysis makes it easier to see that the entire positive quadrant is included in the region of attraction of the stable equilibrium point.

The values for the parameters correspond to the ones used in Narasimhan, Ghosh, and Mendez (1993), by fitting the model to historical data. Quality $(q)$ was set to three different levels: $0.8,0.1$, and 0.1756 , which correspond to the cases $q>,<$, and $=(1 / \alpha M D 2)$, respectively, shown in (13). It is useful to note in passing that $q$ in our discussion is a composite measure of quality scaled in the interval $[0,1]$ for convenience. Figures $1 \mathrm{~A}$ and 1B show, for each of the three values of $q$, the state trajectories for different initial conditions. Because the cases $q=0.1$ and $q=0.1756$ produce identical phase portrait diagrams, they have been combined in Figure 1B.

Useful insights can be gleaned from examining the result in (12) and the phase portraits in Figures 1A and 1B. From (12) it can be seen that $E Q$ which is a measure for quality reputation is a function of product quality $(q)$, quality durability $(D 2)$, product durability $(D 1)$, and the diffusion parameter $\alpha$. It can be seen that equilibrium (i.e., long run) quality reputation can be influenced by four strategic levers, $q, D 1, D 2$, and $\alpha$ of which quality and product durability are in the purview of manufacturing and the other two, D2 (quality durability) and the diffusion parameter which are influenced by advertising and promotion are in the purview of marketing.

Increasing the long run quality reputation of a product depends on the coordinated efforts of marketing and manufacturing. It can be seen that quality reputation $E Q$ is inversely related to product durability $D 1$, which is a surprising result. This is a direct consequence of the explicit consideration of market dynamics in modeling the relationship between sales and product durability. As $D 1$ increases, on average products remain in the market longer, thus increasing market saturation, which makes diffusion of newer products (which carry a current quality message) more difficult. This can, however, be counteracted by manipulating the quality durability $D 2$ through aggressive promotion and advertising. It is useful to note that quality durability $D 2$ appears in two terms in (12), suggesting a strong influence on $E Q$, quality reputation. Analysis of the relationships in (12) shows that adjustments to $D 1$ and $D 2$ must be coordinated to achieve desired long run quality reputation for the product. If $D 1$ is lowered, corresponding to lower values of product durability, pursuant to a "planned obsolescence" strategy or a situation where new products representing significant improvements are introduced often, long run quality reputation $E Q$ is increased which is consistent with experiences of firms. Note that $D 2$, quality durability is closer to the value of product durability $D 1$ as the value of $D 1$ is lowered, implying that there are fewer units in the market that do not influence significantly perceived quality.

This raises the question as to which strategy should be followed. That is, coordinated increase in $D 2$ and $D 1$ or lower $D 1$ by competing through rapid introduction of new products. This strategic choice will depend on the specific market environment in which the product competes, the resources required to manipulate $D 1$ and $D 2$ and how easy it is to manipulate $D 2$, the quality durability. Maytag, the manufacturer of home appliances, which has a solid reputation for the reliability and durability of its products, is an example of a firm that is pursuing a coordinated strategy of high $D 1$ (product durability) and a high $D 2$ (quality durability) through its advertising and promotion that stress its products' quality and durability. Sony is an example of a firm that pursues a low $D 1$ (rapid introduction of new products) and high $D 2$ (aggressive promotion and advertising) for its products.

The strategic importance of quality durability as it affects $E Q$, quality reputation, also stems from the fact that it is a "more flexible" strategy compared to manipulating $D 1$, product durability. Product durability, which is determined by design quality at the time the product is developed, is not as readily manipulable once the product is introduced into the market. However, the choice between these two strategies is also influenced by the cost of manipulating $D 2$ compared to the cost associated with changing $D 1$. The cost benefit tradeoffs 

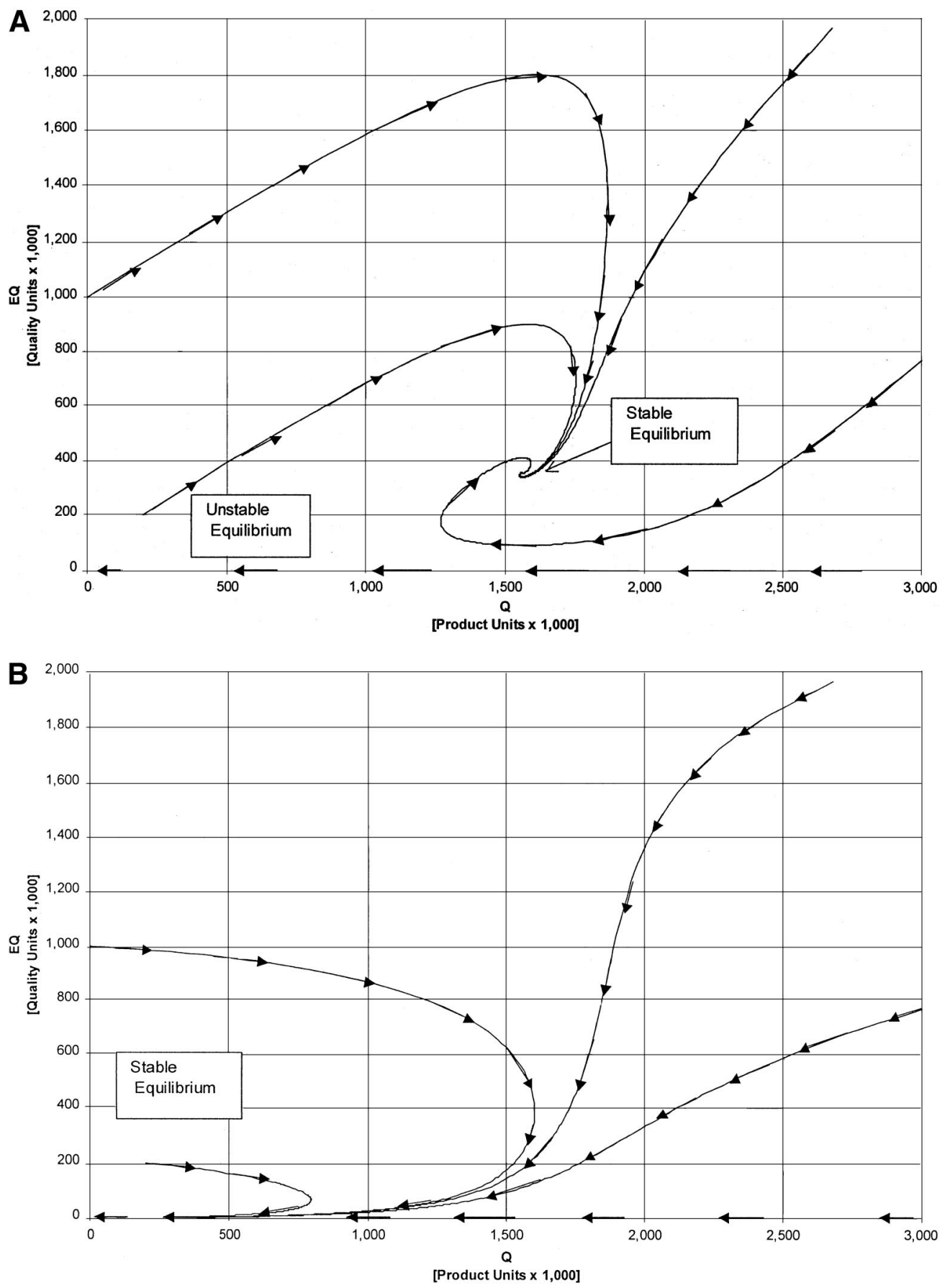

Figure 1A. Phase Portrait Diagram of Proposed Model—Case $q>(1 / \alpha M D 2)$. FIgURE 1B. Phase Portrait Diagram of Proposed Model—Case $q \leq(1 / \alpha M D 2)$.

involved would be amenable to analysis through an approach similar to the one proposed by Wacker (1989).

It can be seen that long run quality reputation is influenced by the quality message carried by each unit into the market. If the quantity of this message is low or if it is poor, promotional strategies may not adequately compensate for it. Appropriate pricing decision, along with 
positioning and promotion might be able to compensate for low quality while the firm "buys" time to improve quality to an acceptably high level. This point underscores the need for better coordination of manufacturing and marketing mix decisions.

The result in (12) is indicative of the strategic importance of quality durability and product durability as components of "manufacturing mix" decisions. That is, regardless of the marketing mix decisions made, since $E Q$ determines the long run sales rate and hence the profitability of the firm, the result in (12) suggests that quality durability and product durability are indeed two independent strategic concepts. To our knowledge mathematical analysis to support this argument is nonexistent in the literature. The result also buttresses the arguments proposed by Skinner (1969) and by Hill (1994) for a more strategic view of manufacturing than is commonly accorded in practice.

The evaluative judgment model (Wacker 1989) would lead one to conclude that as product durability is increased, ceteris paribus, overall (i.e., long run) quality perception will go up, which is opposite of the conclusion that we reach based on our nonlinear dynamic modeling approach. We observe that it is necessary to explicitly disaggregate the dynamics of quality durability and product durability to understand their contributions to long run quality reputation.

From Figure 1A it can be seen that the quality-based strategy of a firm should be to effect moves in a North Easterly direction. North Easterly moves in Figure 1A correspond to higher levels of quality reputation and equilibrium sales rate leading to higher profit levels. Moves along the $x$-axis to the right are accomplished by coordinating quality improvements with appropriate pricing decisions since these affect the sales rate in the long run. Moves along the $y$-axis to the North are influenced by higher values for $q, D 2$ and lower values for $D 1$ and $\alpha$. Viewed in manufacturing terms, we can define quality-based strategy as dynamic positioning of these aspects of quality relative to competition. That is, selecting specific values or targets for price, quality, quality durability, product durability, and the diffusion parameter $\alpha$.

The figures suggest that, with the exception of the $Q$ axis, all the feasible states are included in the region of attraction of the stable equilibrium point. When $q>(1 / \alpha M D 2)$, the state of the system will be attracted to an unstable equilibrium at the origin if $E Q$ ever vanishes. However, any small perturbation that drives the state into positive $E Q$, will make the system converge to the stable equilibrium point.

\section{Results From the Steady-State Analysis}

The analysis of the equilibrium points, under conditions of constant price and quality, reveals a number of interesting steady-state properties of the system and provides important insights into the relationships embedded in the model. The relevant observations that can be derived from the study of the equilibrium points are as follows.

- The model predicts that the state of the system will asymptotically converge to a stable equilibrium point. This implies that, regardless of the initial conditions, sales rate (a function of the state of the system) will eventually stabilize at a constant level. This long run sales rate implied by the equilibrium point

$$
\omega^{b} \text { is } S^{b}=\frac{1}{D 1}\left(\beta P^{-e}-\frac{1}{\alpha q D 2}\right) \quad \text { for } \quad\left(\beta P^{-e}-\frac{1}{\alpha q D 2}\right) \geq 0
$$

- The equilibrium point depends on the quality level. The higher the quality level, the higher the equilibrium values of $Q, E Q$, and $S$. The model implies the existence of a quality threshold (i.e., minimum level of quality) for the equilibrium sales rate to remain positive. A quality level lower than $\left(P^{e} / \alpha \beta D 2\right)$ will drive the sales rate to zero. A quality level higher than $\left(P^{e} / \alpha \beta D 2\right)$ implies that the long run sales rate level is positive. In other words, below this threshold it is not possible to "grow the business." It is interesting 

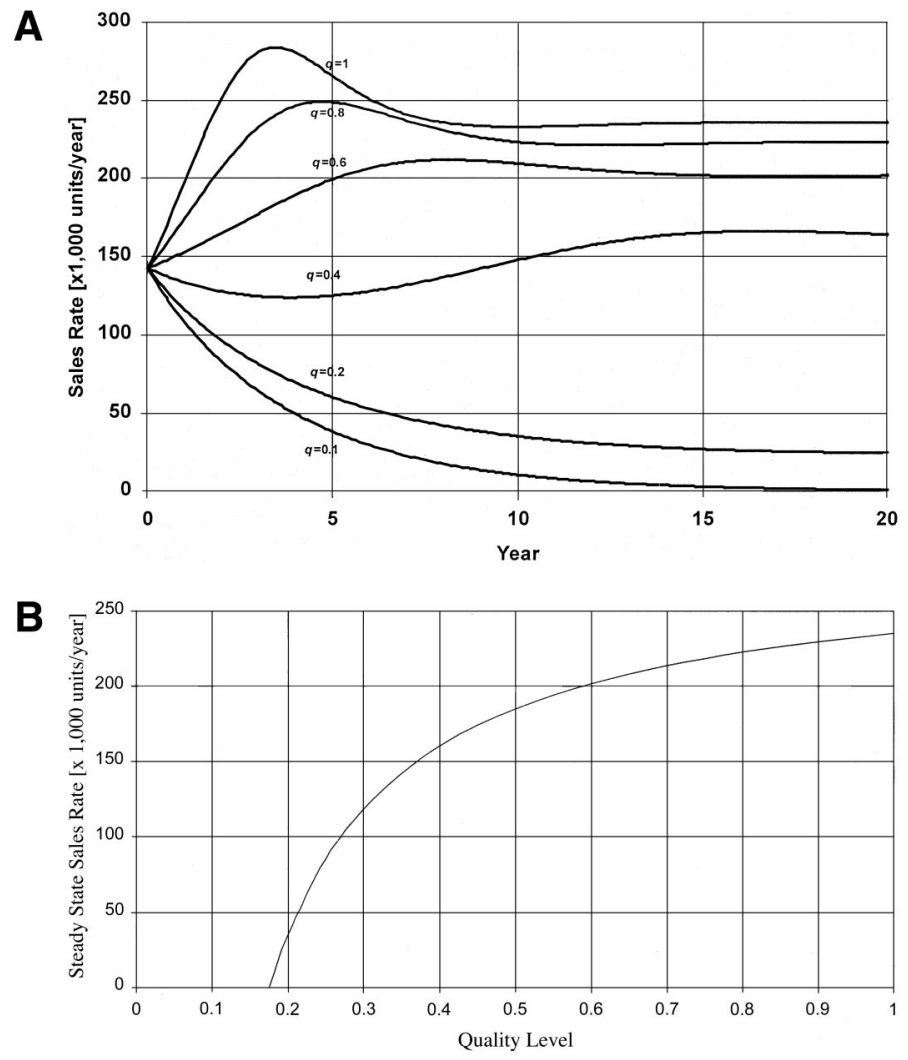

FIgURE 2A. Sales Rate Over Time for Different Levels of Quality.

FIgURE 2B. Steady State Value of the Sales Rate for Different Levels of Quality.

and important to note that the threshold level of quality is a dependent on both price and quality durability. Quality durability's importance is underscored by this relationship also. A firm can ensure that this threshold level of quality is exceeded by lowering price or by increasing $D 2$ or both. This is consistent with pricing durable products low initially (penetration pricing) followed by an increase as the product diffuses through the market and then a monotonic decrease in price as the market for the product matures. It is also interesting to see that, if a firm wants to maintain a certain price but quality level is below the threshold value, then it can increase $D 2$ through promotion and advertising, buying time to improve quality. Equivalently, a threshold level of quality implies that a firm wishing to charge a higher price can opt to manipulate $D 2$, quality durability, without changing quality if the cost of improving quality in the near term is excessively high.

Given the pressures on CEOS to ensure growth in the current business environment, it is important for them to understand the strategic relationship that price, quality durability, and $\alpha$ have on this threshold level of quality. Especially companies entering new markets through product extension strategies must bear this relationship if they are to avoid the disastrous results experienced by Xerox and GE in entering the personal computer market without a coordinated set of marketing and manufacturing mix decisions. Figure $2 \mathrm{~A}$ shows the behavior of the sales rate over time for different levels of quality; Figure $2 \mathrm{~B}$ shows the dependence of the steady-state value of the sales rate on the quality level. In all the results presented in Figure 2, the same parameter values as were used to derive the phase portrait diagrams shown in Figures $1 \mathrm{~A}$ and $1 \mathrm{~B}$ were used. Initial values for $Q$ and $E Q$ were set to 1.5 million and 2 million, respectively.

It can be seen from Figure 2A that the steady-state (long run) levels for sales rate are higher 
for higher levels of quality, underscoring again the strategic nature of quality. By implication we can say that the mathematical analysis has shown that quality is a growth strategy for a durable good. Additional insights can be gained by examining the expression for the steady-state sales rate. Consider the following cases. $D 1$ is "low" corresponding to a product that has a low average life, for example, due to short product life cycle. A case in point might be Intel. Intel has simultaneously manipulated $D 1, Q$, and $D 2$ in that $D 1$ is low due to rapid fire introduction of new products representing high level of innovations, $q$ is high due to the ever increasing speed and performance capabilities of the chips and manipulating $D 2$ through advertising and promotion long before the products are actually introduced in the market. Intel's sales rate is far above that of its principal competitor AMD, which is pursuing primarily a price-based strategy. As was seen in the discussion earlier, the equation for the steady-state value for sales rate also implies that coordinated strategies in marketing and manufacturing can be expected to lead to superior results. In contrast, Maytag, which produces home appliances, represents the case where $D 1$ is "high." The expression for $S$ would suggest that Maytag should manipulate price, quality, and quality durability (D2). Maytag is simultaneously pursuing a quality-based strategy in the sense its products are perceived to be of superior quality, and its promotional strategy emphasizes product quality and durability. These are consistent with what we would infer from the expression for the steady-state sales rate $S$. An examination of Figure 2B, which links steady-state sales rate to quality level, reveals an interesting insight. The relationship is nonlinear, suggesting that there is a decreasing marginal return from quality improvements on profitability. This result is important in that suggests that there is an optimum level of quality beyond which price-based strategies might dominate sales and growth. Earlier it was argued that growth is influenced by $\alpha$, price, quality, $D 2$ (quality durability), and $D 1$ (product durability). The relationship in Figure $2 \mathrm{~B}$ suggests that for a firm that is operating at the flatter portion of the curve (i.e., high level of quality) additional investments in quality improvements (i.e., quality-based strategy) may not be as effective as switching to a price-based strategy, lowering $D 1$ through innovation and radical quality improvements leading to new products or increasing D2 through aggressive and optimal advertising focusing on content, level, and timing of advertisements. This insight is supported by the shift in the strategy of BMw, which is pursuing a price-based strategy, and that of Mercedes Benz, which is pursuing a price-based strategy combined with a promotional strategy for its suv line.

- The model also implies a maximum price level for the sales rate to remain positive. Given that $q_{\min }=\left(P^{e} / \alpha \beta D 2\right)$, and assuming that there is a maximum attainable level for quality $q_{\max }$ (which is equal to 1.0 according to model specifications), the maximum price level for the asymptotic sales rate to remain positive is: $P_{\max }=(\alpha \beta D 2)^{1 / e}$. This result also points out that quality and price are strategically linked! Quality-based benefits do not accrue to a firm automatically. Quality-based initiatives must be coordinated with appropriate pricing decisions. Since quality must exceed the threshold level for it to influence growth in sales, a firm that makes dramatic improvements in quality must ensure that the price is less than the theoretical maximum price. It can be seen that the higher the value of $D 2$, the higher the maximum price. Advertising, which can influence the value $D 2$ as well as $\alpha$, can increase the maximum price, thus giving the firm greater pricing flexibility. This result also underscores the importance of coordinating marketing mix and manufacturing mix decisions.

\section{Summary}

The theoretical analysis presented in this paper investigates the strategic role of quality. It was shown that quality durability and product durability are two independent strategic concepts that influence quality reputation and long-term sales growth and profitability of a firm. Product durability was inversely related to long run quality reputation, which is contrary 
to popularly held beliefs and conclusions one might draw from using some existing frameworks. An explanation was offered for this unexpected and surprising result. The discussion in the paper emphasized the need to disaggregate quality durability and product durability and treat them as two independent concepts. The analysis suggests that this is a much richer conceptualization than aggregating these into composite quality.

Manipulation of quality durability and product durability represents quality-based strategic choices. It was observed that manipulating quality durability might represent a more flexible quality-based strategy than manipulating product durability viewed in terms of cost and time to implement these choices. Quality durability affects quality reputation in important ways. Coordinated moves in product durability and quality durability are necessary for a firm to achieve the desired results, underscoring the importance of manufacturing-marketing linkage that has been stressed in the literature. The specific discussion concerning the coordinated adjustment of product durability and quality durability is a prescription for how and why such adjustments are to be made. To our knowledge, these issues have not been addressed in the literature, and it represents a contribution to the literature dealing with quality-based strategies.

It was shown that there is a minimum level of quality that must be exceeded if a firm wants to grow sales. This threshold level of quality is dependent on both quality durability and product price, underscoring once again the linkage between quality and marketing mix decisions. Analysis of the dependencies suggested by this threshold level of quality suggests how pricing strategies may be coordinated with manipulation of quality durability.

Third, under some conditions, it is better for a firm to move away from a quality-based strategy to other strategies. That is, quality-based strategy loses its effectiveness at relatively high levels of quality, suggesting that there might be an optimum level of quality when quality is viewed in broad terms.

Fourth, firms adopting a product extension strategy must be cognizant of the threshold level of quality and the maximum price that can be charged for a given level of quality. We derived the mathematical results for these two quantities.

\section{References}

Banker, R. D. AND I. S. Khosla (1992), Quality and Competition, Working Paper, Dept. of Operations and Management Science, Carlson School of Management, University of Minnesota, Minneapolis, MN.

Bass, F. M. (1969), “A New Product Growth Model for Consumer Durables," Management Science, 15, $215-227$. , T. V. KRISHnan, And D. C. JaIn (1994), "Why the Bass model fits without decision variables," Marketing Science, 13, 203-223.

Dodds, W. B., K. B. Monroe, And D. Grewal (1991), "Effects of Price, Brand, and Store Information on Buyer's Product Evaluations," Journal of Marketing Research, 28, 307-319.

Flynn, B., R. Schroeder, and S. Sakakibara (1995), "The Impact of Quality Management Practices on Performance and Competitive Advantage,” Decision Sciences, 26, 5, 659-691.

Forrester, J. W. (1968), Principles of Systems. Wright-Allen Press, Cambridge, MA.

FortunA, R. (1990), "The Quality Imperative," in Total Quality: An Executive Guide For The 1990s, Richard D. Irwin, Inc., Homewood, IL.

Gerstner, E. (1985), “Do Higher Prices Signal Higher Quality?” Journal of Marketing Research, 22, $209-215$.

HiLl, T. (1994), Manufacturing Strategy: Text and Cases, Irwin, Boston, MA.

Khalil, H. K. (1992), Nonlinear Systems. Macmillan Publishing Company, New York.

KIM, J. S. (1994), Competitive Gridlock: The Rise and Fall of Continuous Improvements or Beyond the Factory Walls: A First Leap to Overcome Competitive Gridlock. A Research Report of the Boston University School of Management Manufacturing roundtable. Boston, MA.

Krishnan, T. V., F. M. BASS, AND D. C. JAIN (1999), "Optimal Pricing Strategy for new product," Management Science, 45, 1650-1663.

LeE, H. L. AND C. S. TAPIERo (1986), "Quality Control and the Sales Process," Naval Research Logistics Quarterly, 33, 569-587.

Mahajan, V., E. Muller, And F. M. Bass (1990), "New Product Diffusion Models in Marketing: A Review and Directions for Research," Journal of Marketing, 54, 1-26. 
Manetsch, T. J. And G. L. PARK (1982), Systems Analysis and Simulation with Applications to Economic and Social Systems, Michigan State University, East Lansing, MI.

Mendez, D. And R. NARAsimhan (2000), Mathematical Derivation of the NGM Model, Working Paper, Department of Health Management and Policy, University of Michigan, Ann Arbor, MI.

Monroe, K. B. And W. B. Dodds (1988), "A Research Program for Establishing the Validity of the Price-Quality Relationship," Journal of the Academy of Marketing Science, 16, 151-168.

Narasimhan, R. AND S. Ghosh (1994), “A Dynamic Model of Manufacturing Quality's Effect on Optimal Advertising and Pricing Policies,” European Journal of Operational Research, 72, 485-502.

$\longrightarrow, \ldots$, AND D. Mendez (1993), “A Dynamic Model of Product Quality and Pricing Decisions on Sales Response,” Decision Sciences, 24, 5, 893-908.

, D. MendeZ, AND S. GHosh (1996), "An Examination of the Effect of Continuous Quality Improvements on Optimal Prices for Durable Goods," Decision Sciences, 27, 3, 389-413.

Plunkett, J. J. And B. G. Dale (1988), "Quality Costs: A Critique of Some Economic Cost of Quality Models," International Journal of Production Research, 26, 11, 1713-1726.

Rao, A. R. And K. B. Monroe (1989), “The Effect of Price, Brand Name, and Store Name on Buyer's Perceptions of Product Quality: An Integrated Review," Journal of Marketing Research, 26, 351-357.

Shank, J. K. And V. Govindarajan (1993), Strategic Cost Management, Free Press, New York.

Skinner, W. (1969), "Manufacturing-Missing Link in Corporate Strategy," Harvard Business Review, 136-145.

Simon, C. P. AND L. Blume (1994), Mathematics for Economists, W. W. Norton \& Company, Inc., New York.

TApiero, C. S., P. H. Ritchken, And A. Reisman (1987), "Reliability, Pricing and Quality Control," European Journal of Operational Research, 31, 37-45.

WACKeR, J. G. (1989), “An Integrative Theory of Strategic Quality Management: A Cost-Benefit Framework for Evaluating Quality Improvement Programmes,” International Journal of Production Research, 27, 1, 53-71.

Ram Narasimhan is a University Distinguished Professor and Professor of Operations Management in the Eli Broad Graduate School of Management at Michigan State University. He holds a B.S.M.E., M.S.I.E. and received a Ph.D. in Management Science from the University of Minnesota. He has published extensively in operations management and supply chain management in such journals as Management Science, Decision Sciences, Journal of Operations Management, IEEE Transactions, International Journal of Production Research, European Journal of Operations Research and this journal. He is a Fellow of the Decision Sciences Institute and a Fellow of the Pan Pacific Business Association.

David Mendez is an Assistant Professor in the School of Public Health at the University of Michigan. He holds a Ph.D. in Management Science and Operations Management from Michigan State University. David's primary research interests are in dynamic modeling, quality management and health care management issues. He has published extensively on these topics in Decision Sciences, IEEE Transactions, Journal of Supply Chain Management and this journal. 